\title{
Implementation of Control System for Hydrokinetic Energy Converter
}

\author{
Katarina Yuen, Senad Apelfröjd, and Mats Leijon \\ Division of Electricity, Department of Engineering Science, Uppsala University, P.O. Box 534, 75121 Uppsala, Sweden \\ Correspondence should be addressed to Katarina Yuen; katarina.yuen@angstrom.uu.se
}

Received 24 September 2012; Revised 21 March 2013; Accepted 22 March 2013

Academic Editor: Pierluigi Siano

Copyright (C) 2013 Katarina Yuen et al. This is an open access article distributed under the Creative Commons Attribution License, which permits unrestricted use, distribution, and reproduction in any medium, provided the original work is properly cited.

\begin{abstract}
At Uppsala University, a research group is investigating a system for converting the power in freely flowing water using a verticalaxis turbine directly connected to a permanent magnet generator. An experimental setup comprising a turbine, a generator, and a control system has been constructed and will be deployed in the Dalälven river in the town of Söderfors in Sweden. The design, construction, simulations, and laboratory tests of the control system are presented in this paper. The control system includes a startup sequence for the turbine and load control. These functions have performed satisfactorily in laboratory tests. Simulations of the system show that the power output is not maximized at the same tip-speed ratio as that which maximizes the turbine power capture.
\end{abstract}

\section{Introduction}

Unregulated rivers, tides, and other ocean currents comprise a renewable energy resource that may contribute to mankind's energy use. At Uppsala University, a research group is investigating a system for converting the power in freely flowing (undammed) water using a vertical axis turbine directly connected to a permanent magnet generator [1-4].

Several ideas for converting flowing water into electricity are under investigation worldwide, with both companies (http://www.orpc.co/, http://www.marineturbines.com/, http://verdantpower.com/, http://www.hammerfeststrom .com/, http://www.cleancurrent.com/, http://www.openhydro.com/home.html, http://www.minesto.com/) and academic research groups (http://www.eng.ox.ac.uk/tidal, http:// oelab.naoe.inha.ac.kr/, http://www.energy.soton.ac.uk/marine/marine.html) as actors. The predominant concept is to use a turbine to transfer power from the flowing water to a shaft, possibly including a gear-box, and then use a generator to convert the mechanical torque on the shaft to electricity, which then can be transferred to an electric grid.

The concept studied at Uppsala Universtity entails a crossflow, fixed-pitch turbine and a directly driven permanentmagnet generator. By using a directly driven generator and a fixed-pitch turbine, the mechanical complexity of the unit is limited, thus reducing the expected need for maintainance. The generator can be placed outside of the flow through the turbine, and a turbine with a vertical axis can utilize water currents from any direction in the horizontal plane. Challenges pertained to this concept involve the low rotational speed of the generator, and as in all other hydrokinetic energy projects, creating systems that can function well enough in the aquatic environment they are subjected to, withstanding forces, corrosion, biofouling, and floating debris.

The research group at Uppsala University is currently finalizing an experimental station to be deployed in the Dalälven river in the town of Söderfors $[5,6]$. This paper describes the control system implemented at the test-site and some simulations of the system.

\section{The Söderfors Experimental Setup}

The purpose of the Söderfors project is to build and test a system for converting hydrokinetic power to electricity in a natural setting for an extended period of time. The project involves building and deploying a vertical-axis turbine, a directly connected permanent-magnet generator, a control system, and an on-land station to which the power is delivered. 
2.1. Site. The site chosen for the experimental turbine and generator is in a river, Dalälven, in Sweden. In the town of Söderfors, a hydropower plant regulates the river. The outlet channel of the hydropower plant is about $1 \mathrm{~km}$ long. At the end of the channel, a bridge for the main road through the town crosses the river. Near the bridge, the water depth is between 6 and 7 meters. The width of the river is approximately $100 \mathrm{~m}$ (see Figure 1).

Velocity measurements were combined with discharge data for a period of five years. From this, it was found that the velocity on the downstream side of the bridge was mostly around $1-1.4 \mathrm{~m} / \mathrm{s}$ and that the maximum velocity was about $1.9 \mathrm{~m} / \mathrm{s}$. Low velocities, under $2 \mathrm{~m} / \mathrm{s}$, are of interest to the research group, since the ability to utilize such sites would increase the number of possible sites for hydro-kinetic energy conversion.

Parameters considered when looking for a suitable site for an experimental station included velocity distribution, depth, deployment possibilities, proximity to Uppsala, and likelyhood to acquire permits. Information about the site and proposed experimental equipment have previously been published [5-7].

2.2. Turbine. The turbine for the Söderfors station is a fivebladed vertical-axis turbine with fixed blade pitch. Blades and struts are made of a carbon fiber reinforced polymer and attached to a central hub made of steel. The profiles are NACA 0021 , with a chord length of $0.18 \mathrm{~m}$. The radius is $3 \mathrm{~m}$ and the height $3.5 \mathrm{~m}$. Simulations, as described previously $[5,6]$, predict a maximum power capture $C_{p}$ of about 0.36 obtained at a tip-speed ratio $\lambda$ of $3.5 \mathrm{in} 1.3 \mathrm{~m} / \mathrm{s}$ (see Table 1 ).

2.3. Generator. The turbine and generator share a shaft; that is, there is no gear-box. With velocities mostly in the order of $1-1.4 \mathrm{~m} / \mathrm{s}$ and an expected best $\lambda$ of 3.5 , the rotational speed of the turbine and generator is expected to be mainly in the range of $10-15 \mathrm{rpm}$.

The generator design for the Söderfors station is based on the laboratory prototype described earlier [8]. To ease production, the outer diameter of the stator was reduced to $1800 \mathrm{~mm}$. In order to improve efficiency at lower rotational speeds, the axial length has been reduced by designing for a lower voltage [5]. The resulting generator has 112 poles and a line to line voltage of $138 \mathrm{~V}$ at the design point of $1.3 \mathrm{~m} / \mathrm{s}$. See Table 1 for a summary of turbine and generator data.

\section{Control System Design}

The control system is to be able to operate the turbine and generator in different ways enabling experiments for characterizing the setup as well as identifying and evaluating different control strategies. This involves being able to keep a specified rotational speed as well as allowing for implementation of different control algorithms. At the same time, extensive measurements of at least voltages, currents, and rotational speed should be possible. Water current speed should also be measured and related to the system operation, but at the time

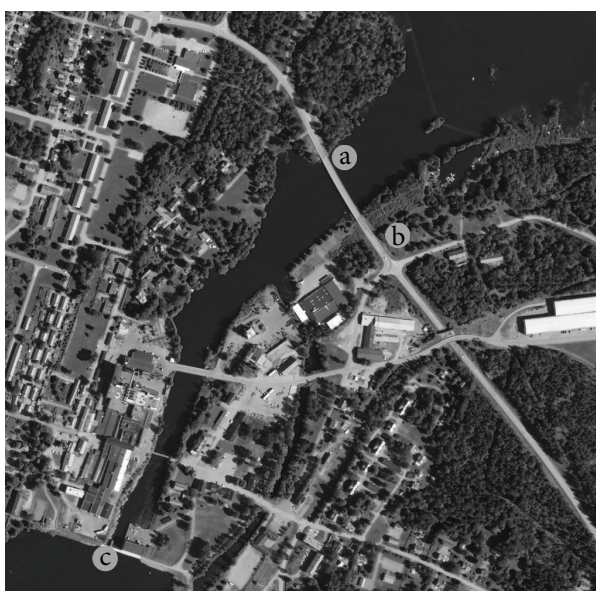

FIgURE 1: Aerial view of Söderfors. The turbine and generator will be installed on the downstream side of the bridge (a), the control station will be situated about $150 \mathrm{~m}$ from the turbine (b). A hydropower station is situated upstream from the site (c).

TABLE 1: Design data for Söderfors turbine and generator.

\begin{tabular}{|c|c|}
\hline \multicolumn{2}{|c|}{ Turbine } \\
\hline Height & $3.5 \mathrm{~m}$ \\
\hline Radius & $3.0 \mathrm{~m}$ \\
\hline No. of blades & 5 \\
\hline \multicolumn{2}{|c|}{ Generator } \\
\hline Stator outer radius & $1800 \mathrm{~mm}$ \\
\hline Stator inner radius & $1635 \mathrm{~mm}$ \\
\hline Air gap & $7 \mathrm{~mm}$ \\
\hline No. of poles & 112 \\
\hline Magnet thickness & $10 \mathrm{~mm}$ \\
\hline Design power & $7.5 \mathrm{~kW}$ \\
\hline Design speed & $15 \mathrm{rpm}$ \\
\hline Design line-to-line voltage (rms) & $138 \mathrm{~V}$ \\
\hline
\end{tabular}

of designing the control system it was not known if continuous real-time velocity data would be available or not. Other parameters, such as mechanical torque, forces on blades, and vibrations, were of interest but considered too much of a complication for a first unit. Conversion to grid specifications and grid connection was also set aside at this stage but can be incorporated later.

3.1. Load Control. The basic theory concerning the operation of a hydro-kinetic energy converter is very similar to that for a wind power plant, which can be studied in textbooks $[9,10]$. Differences relate to the higher density of water, the presence of the water surface, turbulence, and predictability of the resouce, to name some.

The turbine captures a portion of the power in the water that passes it, $P_{\text {turbine }}$ :

$$
P_{\text {turbine }}=\frac{1}{2} C_{p} A_{\text {turbine }} \rho v^{3} \quad[\mathrm{~W}]
$$


$A_{\text {turbine }}$ is the cross-sectional area of the turbine, $v$ is the water velocity, $\rho$ is the density of water, and $C_{p}$ is the power coefficient describing what portion of the available power the turbine captures.

The power capture roughly depends on the relative velocity of the blades to the water, or the tip-speed ratio, $\lambda$, defined as:

$$
\lambda=\frac{\Omega r}{v}
$$

where $\Omega$ is the rotational speed of the turbine and $r$, the radius of the turbine. For the five-bladed, vertical-axis turbine designed for Söderfors, a simulated power capture curve at $1.3 \mathrm{~m} / \mathrm{s}$ is presented in Figure 2 . While the $C_{p}-\lambda$ characteristics change a little with the water velocity, the power capture for this turbine is expected to be at its highest when the tipspeed ratio is around 3.5.

The generator has an efficiency of up to about $85 \%$, according to simulations. The losses in the generator are mainly copper losses (resistive losses in the copper winding) and iron losses (mainly hysteresis and eddy current losses) in the stator steel. These losses depend on both the rotational speed of the generator and the load, or the current, withdrawn from it. For a given power, a higher rotational speed results in a higher voltage and a lower current, giving lower copper losses and higher iron losses. As seen previously [11], the iron losses tend to dominate at lower rotational speeds and the copper losses at higher rotational speeds for a similar machine, provided that the rotational speed is controlled to maintain the tip-speed-ratio where $C_{p}$ is maximal.

The turbine and generator have the same shaft and thus the same rotational speed. The change of rotational speed depends on the power capture of the turbine and the power extraction from the generator to the load, $P_{\text {load }}$, as well as losses in bearings, seals, and the generator. With $J$ as the moment of inertia,

$$
\frac{d}{d t}\left(\frac{1}{2} J \Omega^{2}\right)=P_{\text {turbine }}-P_{\text {load }}-P_{\text {losses }} \quad[\mathrm{W}] .
$$

If the power is not extracted, the rotational speed will increase, and vice versa the speed can be reduced by increasing the power delivered to the load. The change in rotational speed gives a different tip-speed-ratio $\lambda$ and thus a different power capture coefficient, $C_{p}$.

Generally, the variations in water speed should be followed by the generator and turbine, giving a high energy yield. For example, if the $C_{p}$ characteristics of the turbine and the water speed are known, a specific tip-speed ratio can be upheld. If the maximum $C_{p}$ and corresponding tip-speed ratio, $\lambda_{0}$, are known, but not the water velocity, the velocity may be estimated by evaluating the absorbed power and the rotational speed, for example, from (1) we have the following

$$
v=\sqrt[3]{\frac{2 P_{\text {turbine }}}{C_{p}^{\max A \rho}}} \quad[\mathrm{m} / \mathrm{s}],
$$

where $P_{\text {turbine }}=P_{\text {load }}+P_{\text {losses }}$ if the rotational speed is constant. Using (2), we see that the power handled by the

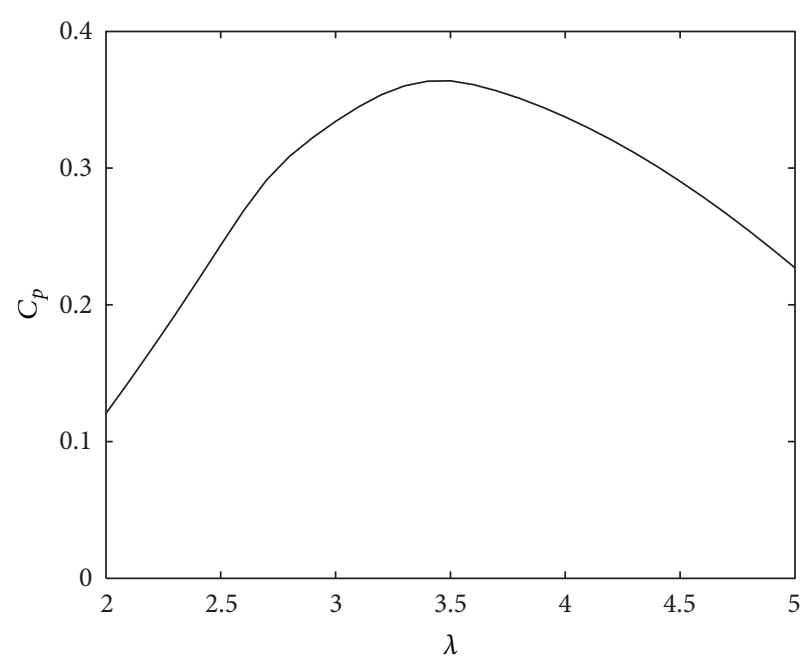

FIGURE 2: Simulated $C_{p}$-curve at $1.3 \mathrm{~m} / \mathrm{s}$ for the turbine designed for Söderfors according to the streamtube model.

generator should be proportional to the rotational speed cubed, $\Omega^{3}$. Or, we can express the electromagnetic torque as follows

$$
M_{e}=\frac{r^{3}}{2 \lambda_{0}} \rho C_{p}^{\max } A \Omega^{2} \quad[\mathrm{Nm}] .
$$

If the $C_{p}$ is unknown, a control scheme called maximum power point tracking, MPPT, may be employed, where the load is regularly perturbated in order to find an operating point where the output power is at a maximum [10].

From a system perspective, the best way to control the turbine and generator is not easily defined. On the one hand, maximizing energy output is an attractive feature. At the same time, all equipment, including the grid connection, needs to be dimensioned for the maximum output power. If this power is seldom reached, maximizing energy output may be expensive. Instead, it may be cost-efficient to install for a smaller power and obtain a higher degree of utilization, as suggested by Clarke et al. [12].

Another aspect is the wear of the equipment. Different operating conditions result in different mechanical loads on the machine as discussed by $\mathrm{Hu}$ and $\mathrm{Du}$ [13]. Control algorithms in relation to mechanical loads can be analyzed, as in wind power [14], and allowed to influence the design of turbines and generators. Fault ride through is also an issue that has been addressed in wind power [15], and much work may be applicable also in the case of hydro-kinetic energy.

Also note that the highest power capture for the turbine may not correspond to the highest system power output due to the characteristics of the losses in the generator and other electrical components, as well as frictional losses, as they may vary with rotational speed and load. With a generator with low rotational speed, an increase in rotational speed may result in an increase in efficiency due to increased voltage, 
which outweighs the decrease in power capture, to some degree. This corresponds to operation at a tip-speed ratio higher than that which gives maximal $C_{p}$, which in turn means that when stopping the turbine, the power will initially increase.

Yet another issue relates to the cost of determining different parameters. Finding the $C_{p}$-characteristics for the turbine, or the equivalent for the whole system, involves initial full-scale tests over a range of velocities. Measuring water velocity and providing real-time data to a control system introduce an extra complexity of the system in the form of measurements, but also transfer of the data.

The variations in water speed at different sites have different characteristics; tides are highly predictable, local air pressure and precipitation may have a strong effect on some sites. Different control strategies may be more or less appropriate at a specific site.

Given these issues related to the control of a hydrokinetic energy converter, the control system for the Söderfors station should be able to extract power from the generator so as to maintain a specified rotational speed, thus enabling the implementation of various control strategies. The control system should also enable a controlled stopping of the turbine and generator.

3.2. Start-Up Theory. The control system is also required to be able to start the turbine. The turbine may be able to selfstart under certain conditions, but it is not expected to do so generally. Instead, the turbine can be accelerated using the generator as an electric motor. At a sufficient rotational speed, the turbine will extract power from the water current, and the control system can switch from start-up to load control. A similar electric start system, though using an auxiliary winding, has been constructed and tested for use with a vertical-axis wind turbine. The energy needed to start the turbine was approximately equal to the energy produced during 3 s nominal operation [16].

During start-up, the permanent magnet machine can be used as a brushless DC motor (BLDC), for which there are established means of operating [17]. A DC-source feeds an inverter which in turn is connected to the three phases of the motor. Knowing the position of the rotor, one can determine which phases to deliver current to in order to accelerate the motor. The rotational speed will then be proportional to the DC-voltage, but by using pulse width modulation (PWM), a lower effective voltage can be obtained. Increasing the duty cycle (on time) of the PWM, the voltage, and thus the rotational speed of the rotor and turbine, can be increased gradually.

The position of the rotor can be determined using Hall effect sensors placed near the rotor. Three sensors positioned $120^{\circ} \mathrm{e}$ (electrical degrees) apart give six different states that can be used to control the inverter. It is also possible to determine the rotor position without sensors mounted in the generator by analyzing the back emf from the machine. For the Söderfors setup, it was decided to install sensors in the machine, thus enabling start-up with sensors, but not excluding the possibility of designing a sensorless start.
3.3. Emergency Brake and Standstill. In the event that the turbine and generator need to be halted abruptly, an emergency brake should be present. A short circuiting of the generator could serve as an emergency brake but may harm the turbine due to the high torque involved. A dampened short circuit, essentially, providing the generator with a high load (low $\mathrm{Ohm}$ ), should also be able to brake the turbine quickly, but somewhat more mildly.

Once at standstill, a short circuit of the generator should prevent it from self-starting.

3.4. Control System Topology. The topology for the control system, given that no power is delivered to the grid, is illustrated in Figure 3. The three phases of the generator can be connected to four different parts of the control system.

For starting the generator and turbine, a DC-source in the form of a three-phase transformer and a diode rectifier feeds an inverter. The load control comprises a rectifier, a capacitor bank, a resistive load, and an IGBT (insulated gate bi-polar transistor) to determine the amount of power spent in the load. The load IGBT is controlled with a PWM signal, and the duty cycle (on time) determines how much power is extracted for a given voltage. The emergency brake is a Y-connected load.

3.5. Simulations. Each branch (a, b, c, and d) in Figure 3 has been separately implemented in Matlab Simulink (Mathworks, http://www.mathworks.com/). Simulations were used to dimension components in the control system and to gain some knowledge of how the system would respond.

In Simulink, the existing permanent magnet synchronous machine was used to simulate the generator. No iron losses are included in this model and were not added at this point. Frictional losses in bearings and seals have also been neglected. See Table 2 for a summary of input data used. Figure 4 shows the Simulink model representing load control of the Söderfors generator and turbine. The turbine $C_{p}$ is implemented as a lookup table. The water speed is specified, and the duty cycle is regulated to reach a desired rotational speed. The cable for power transmission between the generator and the control station is added as $0.1 \Omega$ resistance per phase.

\section{Realization of Control System}

In general, the control system is intended to be easy to become familiar with. It is not viewed as a final product, rather a first version of itself, allowing for further development, and tests not yet concieved. At an early stage, it was decided to let the submerged turbine and generator be connected to an on-land control station via an enclosure mounted on the bridge railing about $40 \mathrm{~m}$ from the generator, to enable convenient deployment, as well as provide space for extra equipment that may be needed close to the water.

Most of the control system, described in more detail below, is collected in the enclosure shown in Figure 5. The power cable from the generator is connected (a). Contactors and fuses connect and disconnect the different branches of 


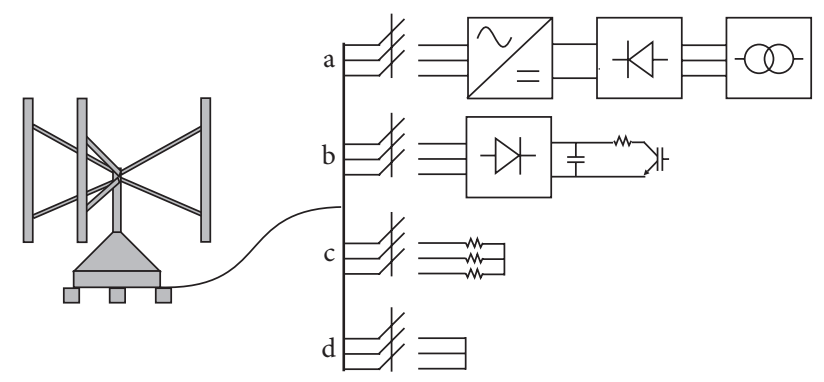

Figure 3: Schematic illustration of the control system. The turbine and generator have a common shaft. The three phases of the generator can be connected to different parts of the control system. (a) shows startup (right to left) where a DC source feeds an inverter which is controlled to start the machine, (b) is the regular controlled load, (c) is an emergency brake, and (d) is the parking brake.

TABLE 2: Permanent magnet synchronous machine in Simulink.

\begin{tabular}{lc}
\hline Back EMF waveform & Sinusoidal \\
Mechanical input & Torque \\
Stator phase resistance & $0.335 \Omega$ \\
Inductances $\left(L_{d}=L_{q}\right)$ & $3.5 \mathrm{mH}$ \\
Flux linkage & $1.29 \mathrm{Vs}$ \\
Inertia & $2445 \mathrm{kgm}^{2}$ \\
Initial rotation & $1 \mathrm{rad} / \mathrm{s}$ \\
\hline
\end{tabular}

the control system (b). A diode rectifier is mounted on a heat sink (c), capacitors are mounted in a separate enclosure (d), and two IGBT's (for redundancy) control the load. The inverter used for start-up is mounted on a heat sink (f). The short circuit that serves as a parking brake is manually operated $(\mathrm{g})$.Voltage and current measurements are collected in three printed circuit boards mounted in zink boxes (h). The CompactRIO (i) is the interface between hardware and software.

LabView and a CompactRIO from National Instruments (http://www.ni.com/) were chosen as software and interface to hardware. The CompactRIO includes a field programmable gate array (FPGA) for small, fast data operations, a real-time processor, and a chassi that can contain four or eight modules. There is a number of different types of modules for digital and analog input and output, relays, and so forth providing the interface needed for both measurements and IGBT drivers. The alternative to this would have been to use a microprocessor and to construct an interface between hardware and software. This solution would perhaps cost less but would be more difficult to build upon and develop.

4.1. Measurement System. Measurements are necessary for the control system but are also wanted for analysis of the experimental setup. These two functions are different: for control of the system, the required sample rate may be lower, data needs to be analyzed quickly, and there is no need to save long data series.

Voltages and electrical currents from the generator are measured on-land, as well as voltage and currents in the load.
From the generator line-to-line voltages of the generator, as well as line-to-neutral voltage of one phase are measured. The load (DC) voltage is measured as well as the voltage from the DC source for start-up. Currents from the generator, from the start system, to the capacitors and to the load are measured. Currents are sensed using current transducers (HAL 100 and HAL 200 from LEM (http://www.lem.com/)). Voltage division by approximately 37 is applied to all voltages. Signals from the current transducers and divided voltages are measured using C-series module NI 9205. Sampling rate can be decided by the user.

Rotational speed is measured using the signal from one of the Hall sensors used for start-up (see below).

As the only visual contact with the generator and turbine, a network camera (AXISM5014) has been installed in the generator, as well as LEDs for light. The network camera can pan, tilt, and zoom and is powered over ethernet.

Torque measurements on the shaft were considered too much of a complication for a first prototype in an aquatic setting. However, torque measurements were possible during lab tests prior to deployment. While designing the control system, it was not known if real-time water current measurements would be available. Should measurements become available, it should be possible to access them via the CompactRIO, or from a computer file.

The main control program consists of two loops: a monitoring loop for processing and storing measurements and a control loop that executes the chosen control operation. New control algorithms should be easy to implement in the control loop as new cases.

4.2. Load Control. Power from the generator is delivered to the control station in three phase cables and a common neutral. The neutral is left ungrounded and is used for measurement of phase voltage.

The three phases are fed to a rectifier and a capacitor bank to stabilize the DC level. The DC power is consumed in a resistive load via an IGBT; see Figure 3(b) in which the circuit is illustrated. The IGBT functions as a switch and is turned on and off with a pulsed signal, the duration (or duty cycle) of which can be controlled, determining the amount of power extracted from the generator and thus controlling the rotational speed of the generator rotor and turbine. See also Figure 5.

The load IGBT is chosen based on simulation results, given a hefty safety margin, and matched with the supplier's current stock, resulting in an SKM400GAL12, which includes a freewheeling diode. An extra IGBT is mounted in parallell for redundancy and can be used alternately if the primary one should falter. The IGBTs chosen are a type previously used within renewable energy projects at Uppsala University. They have performed satisfactorily, and a driver for them has been developed in house. IGBTs are controlled with digital signals from a C-series module NI 9401.

The load is a set of $1 \Omega$ resistors (Vishay RPS 500 series) mounted on heat sinks. The nominal three-phase load for the generator is $2.5 \Omega$ per phase, but an appropriate DC load has been estimated to be approximately $1 \Omega$ or less (depending on 


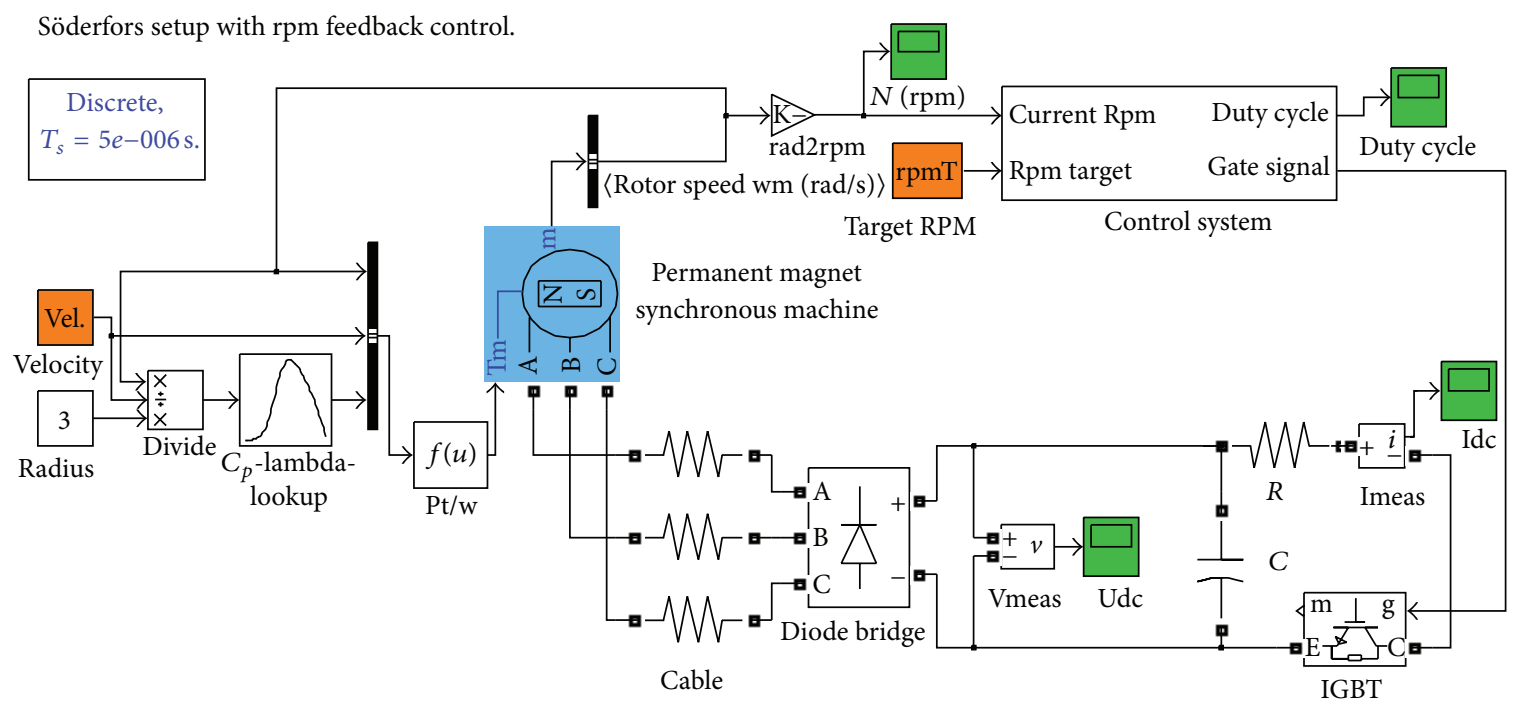

FIGURE 4: Simulink model of the Söderfors turbine and generator with control of rotational speed.

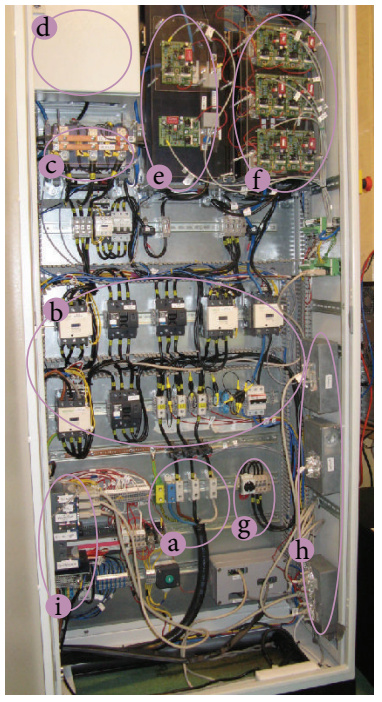

FIGURE 5: The electrical enclosure at the control station. Generator power cable (a), contactors and fuses (b), diode rectifier (c), enclosed capacitors (d), load control IGBT's (e), startup inverter (f), manually operated parking brake $(\mathrm{g})$, voltage and current measurements $(\mathrm{h})$, and CompactRIO (i).

the water current speed and load duty cycle used). Though variable, the default DC load is 30 resistors connected in series and parallel to $5 / 6 \Omega$. Each resistor is rated at $500 \mathrm{~W}$, resulting in a load capacity of $15 \mathrm{~kW}$.

The software implementation of the load control is essentially a control of the duty cycle of the IGBT. A proportional factor (which can be set by the user) is applied to the error between a desired state (e.g., rotational speed) and the actual state.

4.3. Start-Up. The start system includes three Hall latches in the generator to sense the position of the rotor: a DC source in the form of a three-phase transformer and diode bridge, a three-phase IGBT inverter, and a control program.

The three-phase transformer and diode bridge were purchased as a unit from Tramo ETV (http://www.tramoetv.se/). The transformer is connected to a standard three-phase outlet providing it with $400 \mathrm{~V}$ at $50 \mathrm{~Hz}$. It has four taps, giving a secondary voltage of $190,170,150$, or $130 \mathrm{~V}$.

The inverter used for the start consists of three SKM300GB12 IGBTs (two in each) mounted on a heat sink, and driver circuits for each. The IGBTs are controlled by digital signals from a C-series module NI 9401 in the CompactRIO.

The Hall sensors mounted on the stator are latch type sensors, A1210, from Allegro (http://www.allegromicro.com/). Three sensors are mounted on a printed circuit board (PCB) containing supplemental electronic components according to the manufacturer's application notes. The PCB is designed to separate the sensors by 120 electrical degrees in the stator and is screwed onto a plastic mount on the stator before winding see Figure 6 . The diameter of the stator is large enough that the PCB bends to fit the rounding of the stator. Four separate PCBs have been mounted in the stator for redundancy. The Hall sensor signals are read by a C-series module NI 9401.

Software implementation of the startup entails reading the signals from the Hall sensors, identifying which IGBTs to have on, and giving on signals to those IGBTs. A PWM block allows a gradual increase of rotational speed.

4.4. Emergency Brake and Standstill. An emergency brake which can be described as a damped short circuit has also been implemented. Via a mechanical emergency button or at a signal given from the computer program, a three-phase load of $0.5 \Omega$ per phase is applied. Simulations in Simulink have shown that this load should, in an extreme case, be able to stop the turbine within 2 seconds.

At standstill, the generator can be short circuited via a switch in the main enclosure at the control station, as well 


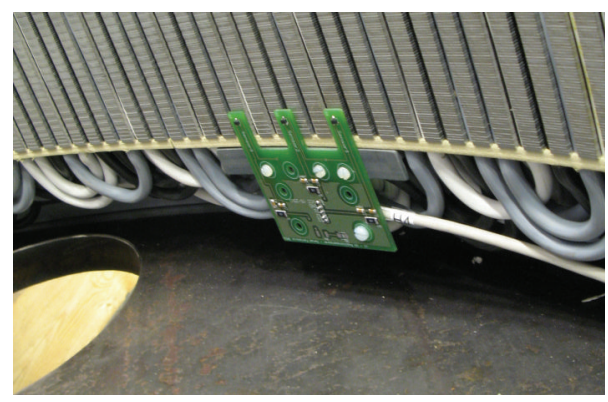

Figure 6: Hall sensors on a PCB screwed to a plastic mount attached to the stator.

as in the bridge enclosure. The turbine is expected to remain fairly still (under $1 \mathrm{rpm}$ ) when short circuited at the control station and even more still when shorted in the bridge enclosure.

4.5. On-Site Installation. The on-site installation comprises a submerged part, that is, the turbine and generator, and an on-land control station with the equipment described above. These two parts need to be connected by power and data cables. In order to facilitate the installation of the equipment, an electrical enclosure is mounted on the bridge railing, about $40 \mathrm{~m}$ from where the generator will be placed. The power and signal cables from the generator have been provided with weather proof connectors that are easily attached to the bridge enclosure. The bridge enclosure also provides a point close to the underwater site where the generator can be short circuited, signals can be amplified if necessary, power over ethernet injected, and so forth; see Figure 7. (Acoustic Doppler Current Profilers (ADCPs) are used for measuring water velocity.)

Cables from the bridge enclosure follow the bridge to land where they are buried until they reach the measurement station, slightly more than $100 \mathrm{~m}$ away. In the station, the power cables are screwed into terminals in the main enclosure, and signal cables are provided with standard connectors. This way, the different parts of the whole setup can be installed separately and also disconnected if necessary. Figure 8 shows the interior of the control station.

\section{Laboratory Tests and Simulations}

The generator for the Söderfors setup was assembled in the laboratory at the university. There, it was also possible to test the performance of the generator and some functions of the control system.

5.1. Laboratory Test of Load Control. The generator was connected to a motor drive that could be torque controlled. In this setup, it was possible to test if the load control system could keep a specified rotational speed and a specified load voltage. Between about 4 and $15 \mathrm{rpm}$ the control system was able to hold a fairly constant rotational speed when the torque was varied. Switching frequencies for the load IGBT was tested from $10-500 \mathrm{~Hz}$. In order to reduce voltage transients

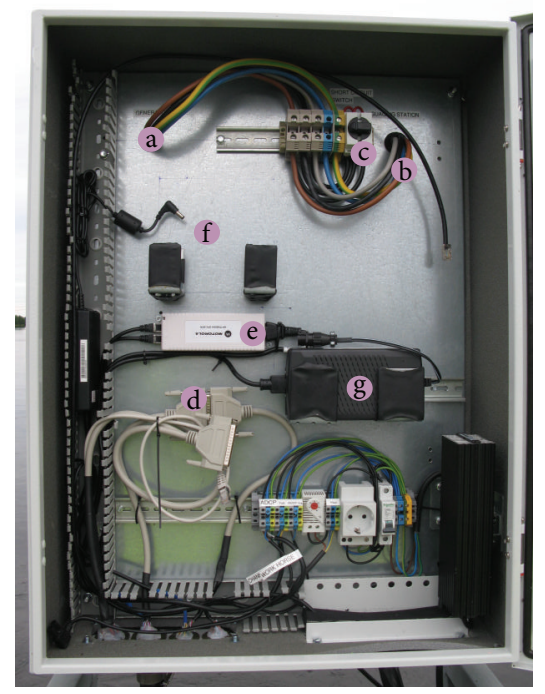

FIGURE 7: Interior of the bridge enclosure. Power from the generator (a) and to the control station (b) can be manually short circuited in (c). Hall sensor and other signals are relayed in (d). (e) provides power for the network camera. A computer for communication with ADCPs will be mounted (f) and the ADCPs need power ( $\mathrm{g}$ ).

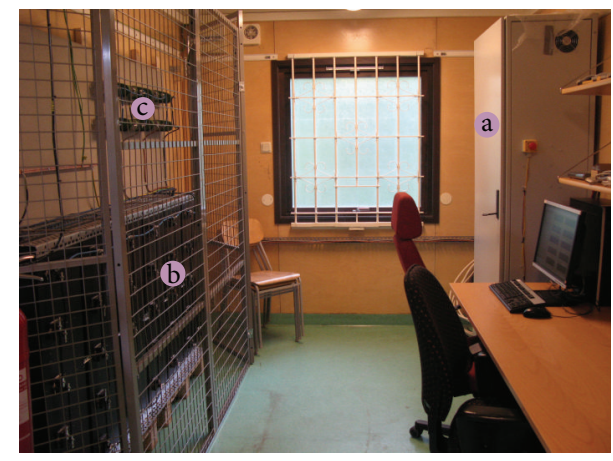

FIgURE 8: The main enclosure (a), the regular load (b), and the emergency stop load (c) in the control room.

over the rectifier, two snubber capacitors of $100 \mathrm{nF}$ each (BFC238670104 http://www.vishay.com/) were added over the IGBT.

Keeping a fixed duty cycle was also tested. Figure 9 shows the line to line voltage and current in one phase of the generator while keeping a fixed duty cycle of $10.5 \%$. Figure 10 shows the voltage and current through the load for the same time period.

5.2. Laboratory Test of Start-Up. Start-up of the generator for Söderfors was tested using laboratory voltage supplies, since the DC source had not yet been decided on. The generator shaft was not connected to anything during this test, that is, neither to the turbine or the motor drive, and the seal on the shaft had not yet been mounted. This means that the start-up situation was simplified in that the friction was reduced, and no torque was delivered from the turbine. However, the start 


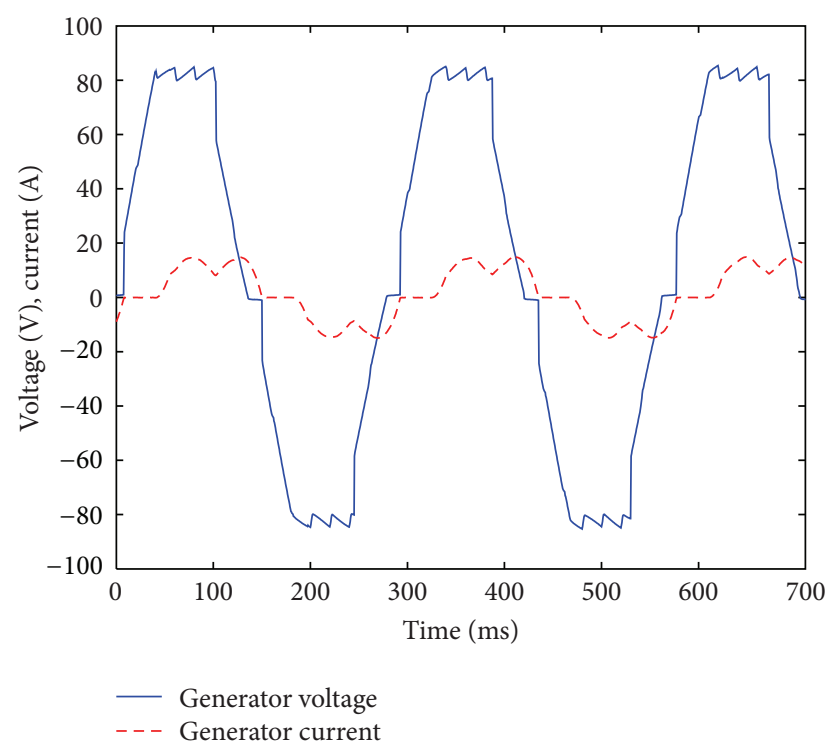

FIGURE 9: Generator voltage (line-to-line) and current while maintaining a $10.5 \%$ duty cycle.

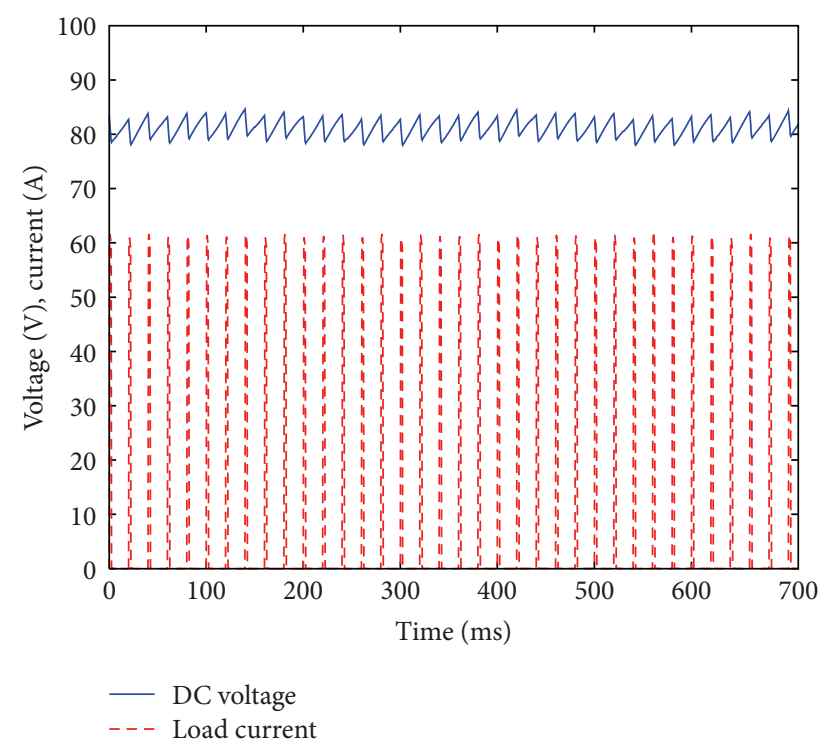

FIGURE 10: Load current and voltage while maintaining a 10.5\% duty cycle.

system was able to rotate the generator smoothly up to $13 \mathrm{rpm}$ (the voltage supplies could not provide higher voltage).

After the rectified transformer had been decided on and delivered, a new start-up test was performed using a similar generator [8] still in the lab. The new DC source does not have the controlled current limitation in it as the laboratory voltage supplies do. This situation gave opportunity to trim the overcurrent protection on the IGBT drivers and provided some practical experience. After some adjustments, the start-up system functioned well.
5.3. Simulation Results. The implementation of the system in Simulink was used for dimensioning components, as mentioned earlier. It was also used to characterize the expected performance of the system. The following figures are a result of a parameter sweep of water velocity and target rpm, stepping $1 \mathrm{rpm}$ and $0.2 \mathrm{~m} / \mathrm{s}$, as well as a sweep of $\lambda=$ 3.5 for the same velocities. The system is initiated with a rotational speed of $1 \mathrm{rad} / \mathrm{s}$ and simulated for $40 \mathrm{~s}$. Data from the last $10 \mathrm{~s}$ are averaged. Where the tip-speed ratio is far from 3.5, it is difficult to reach the target rotational speed. At tip-speed-ratios above 4, the control system is not able to keep a constant rotational speed, rather the speed will oscillate around the target. Also, the control system is not dimensioned for maximum power capture at water speeds as high as $2 \mathrm{~m} / \mathrm{s}$, so as the water speed increases, the control system becomes strained.

In Figure 11 the output power is plotted against the tipspeed ratio, $\lambda$, for different water speeds. As can be seen in the figure, the maximum power output for a given water speed is reached not necessarily at $\lambda=3.5$. Close to the design water velocity, the system power is maximized at approximately the same $\lambda$ as the turbine power capture is maximized at, but for other velocities, a higher $\lambda$ maximized the power output. As mentioned earlier, iron losses are not included in this simulation and may affect the result. However, we see that maximizing the system power output is a different operation than maximizing the turbine power capture. A higher rotational speed will increase the voltage output, thus decreasing the current and, consequently, the copper losses. An increase in rotational speed will increase iron losses, but as shown previously [11, 18], the copper losses dominate in this type of machine at higher water velocities.

Figure 12 shows the power capture of the turbine for $C_{p}=$ 0.36 , the maximum output power for each velocity, and the power output when operating at tip-speed ratio $\lambda_{0}=3.5$. The difference between the maximum power output and the power output at $\lambda_{0}$ increases with the water velocity. This is due to the increased effect of copper losses, and thus the increased benefit of reducing them.

Figure 13 shows the duty cycle (or on time) of the load versus rotational speed for different water velocities. The water velocity is expected to be mostly around $1-1.4 \mathrm{~m} / \mathrm{s}$, and the load control system appears to handle these velocities well with a maximum duty cycle of about 0.5 . At $2 \mathrm{~m} / \mathrm{s}$, the full load capacity of $5 / 6 \Omega$ is used and is not sufficient to control the turbine. With a smaller load resistance, it may be possible to operate at $\lambda \approx 3.5$. The current load is rated at $15 \mathrm{~kW}$, which is possibly sufficient at $1.8 \mathrm{~m} / \mathrm{s}$ given that there are additional losses in the system not incorporated in the simulations.

\section{Conclusions}

A control system for an experimental setup for hydrokinetic energy conversion has been designed and realized. It performs satisfactorily in a laboratory environment but has yet to prove itself when controlling equipment in an aquatic setting. 


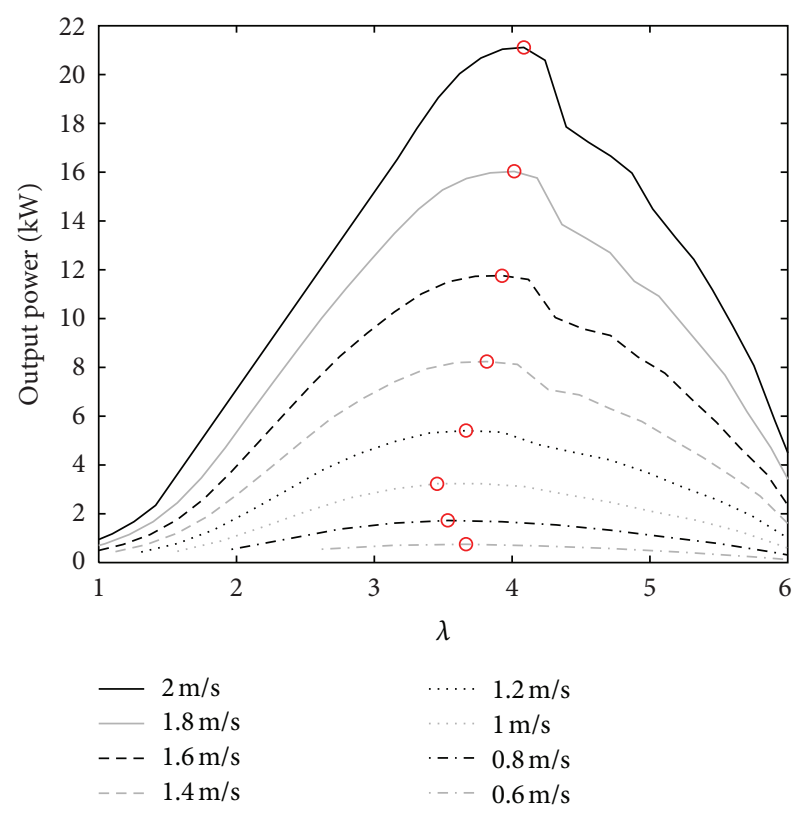

Figure 11: Power output of the system versus tip-speed ratio. The maximum power output for a certain water velocity, marked with a red circle on each curve, is at a higher tip-speed ratio than that which maximizes the turbine $C_{p}$.

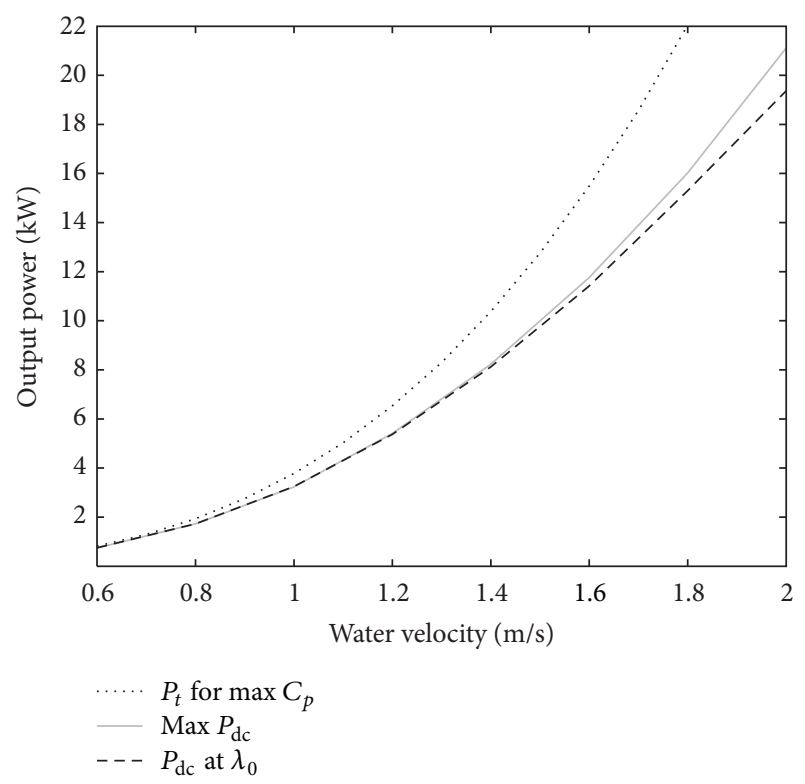

Figure 12: Power capture of the turbine at maximum $C_{p}$, maximum output power for each velocity, and power output for $\lambda=3.5$.

Simulations show that maximizing the energy output of the system may coincide with a higher rotational speed than that resulting in maximum turbine power, especially at higher water velocities. The load control system for Söderfors can handle maximizing the power output within the typical velocity range of $1-1.4 \mathrm{~m} / \mathrm{s}$.

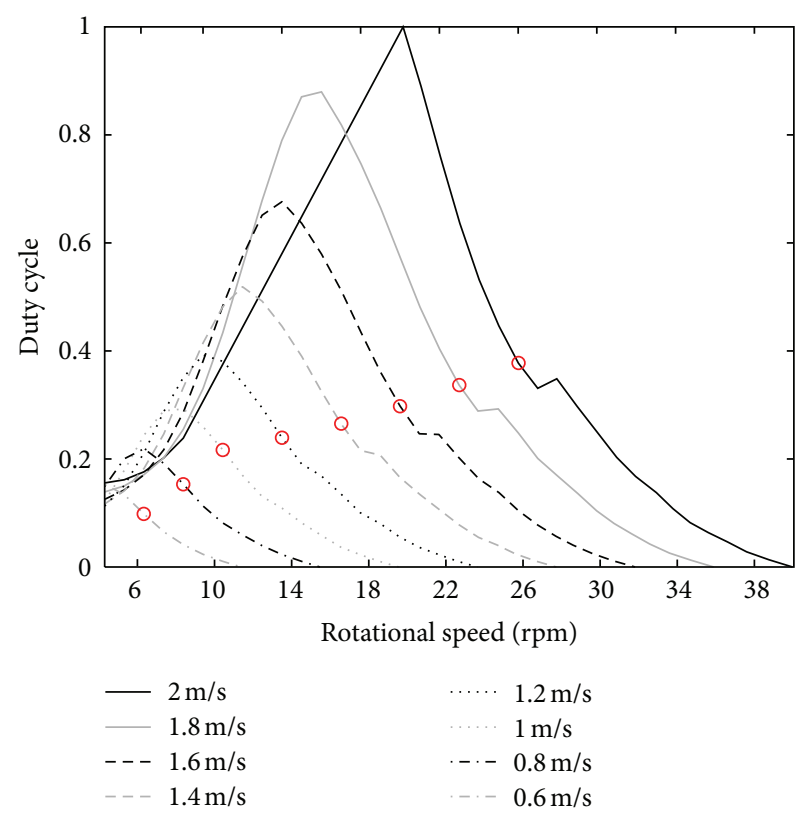

FIGURE 13: Duty cycle of the load versus rotational speed for different water velocities. The operating point with maximum power output is marked in each curve with a red circle.

\section{Acknowledgments}

This work was carried out with support from The J. Gust. Richert Foundation for Technical Scientific Work, STandUp for Energy, The Swedish Research Council (Grant no. 6212009-4946), Vattenfall AB, and Ångpanneföreningen's Foundation for Research and Development. Thanks to the rest of the hydro-kinetics research group for your efforts and general support. Mårten Grabbe designed and built the generator. Anders Goude modeled the turbine. Emilia Lalander and Staffan Lundin characterized the Söderfors site. Thanks to Jon Kjellin, Fredrik Bülow, and Rickard Ekström for supportive discussions.

\section{References}

[1] K. Thomas, Low speed energy conversion from marine currents [Ph.D. thesis], Uppsala University, 2007.

[2] K. Yuen, System aspects of marine current energy conversion [Licentiate thesis], Uppsala University, 2008.

[3] M. Grabbe, Marine current energy conversion-resource and technology [Licentiate thesis], Uppsala University, 2009.

[4] E. Lalander, Modelling the hydrokinetic energy resource for instream energy converters [Licentiate thesis], Uppsala University, 2010.

[5] M. Grabbe, K. Yuen, A. Goude, E. Lalander, and M. Leijon, "Design of an experimental setup for hydro-kinetic energy conversion," International Journal on Hydropower and Dams, vol. 16, no. 5, pp. 112-116, 2009.

[6] K. Yuen, S. Lundin, M. Grabbe, E. Lalander, A. Goude, and M. Leijon, "The Söderfors project: construction of an experimental hydrokinetic power station," in Proceedings of the 9th European Wave and Tidal Energy Conference (EWTEC '11), pp. 1-5, Southampton, UK, September 2011. 
[7] E. Lalander and M. Leijon, "Numerical modeling of a river site for in-stream energy converters," in Proceedings of the 8th European Wave and Tidal Energy Conference (EWTEC '09), pp. 826-832, Uppsala, Sweden, 2009.

[8] K. Thomas, M. Grabbe, K. Yuen, and M. Leijon, "A low speed generator for energy conversion from marine currentsexperimental validation of simulations," Proceedings of the IMechE A: Journal of Power and Energy, vol. 222, no. 4, pp. 381$388,2008$.

[9] J. Manwell, J. McGowan, and A. Rogers, Wind Energy Explained-Theory, Design and Application, John Wiley \& Sons, Chichester, UK, 2002.

[10] I. Munteanu, A. I. Bratcu, N.-A. Cutululis, and E. Ceangă, Optimal Control of Wind Energy Systems, Towards a Global Approach, Advances in Industrial Control, Springer, 2008.

[11] K. Yuen, K. Thomas, M. Grabbe et al., "Matching a permanent magnet synchronous generator to a fixed pitch vertical axis turbine for marine current energy conversion," IEEE Journal of Oceanic Engineering, vol. 34, no. 1, pp. 24-31, 2009.

[12] J. A. Clarke, G. Connor, A. D. Grant, and C. M. Johnstone, "Regulating the output characteristics of tidal current power stations to facilitate better base load matching over the lunar cycle," Renewable Energy, vol. 31, no. 2, pp. 173-180, 2006.

[13] Z. Hu and X. Du, "Reliability analysis for hydrokinetic turbine blades," Renewable Energy, vol. 48, pp. 251-262, 2012.

[14] E. A. Bossanyi, “The design of closed loop controllers for wind turbines," Wind Energy, vol. 3, no. 3, pp. 149-163, 2000.

[15] G. Mokryani, P. Siano, A. Piccolo, and Z. Chen, "Improving fault ride-through capability of variable speed wind turbines in distribution networks," IEEE Systems Journal, 2012.

[16] J. Kjellin and H. Bernhoff, "Electrical starter system for an Hrotor type VAWT with PM-generator and auxiliary winding," Wind Engineering, vol. 35, no. 1, pp. 85-92, 2011.

[17] T. L. Skvarenina, The Power Electronics Handbook, Industrial Electronics, CRC Press, 2002.

[18] S. Eriksson and H. Bernhoff, "Loss evaluation and design optimisation for direct driven permanent magnet synchronous generators for wind power," Applied Energy, vol. 88, no. 1, pp. 265-271, 2011. 

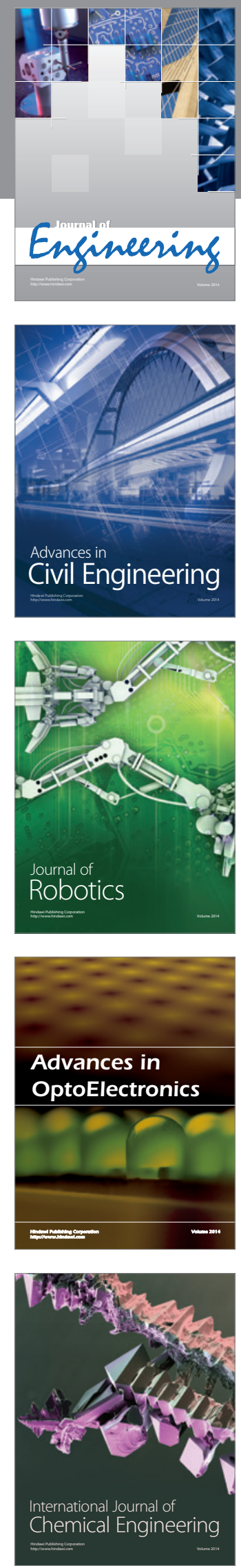

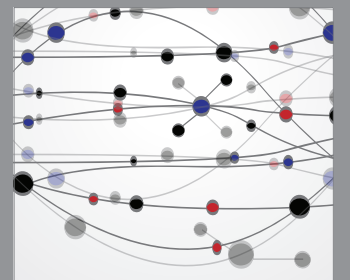

The Scientific World Journal


Submit your manuscripts at http://www.hindawi.com
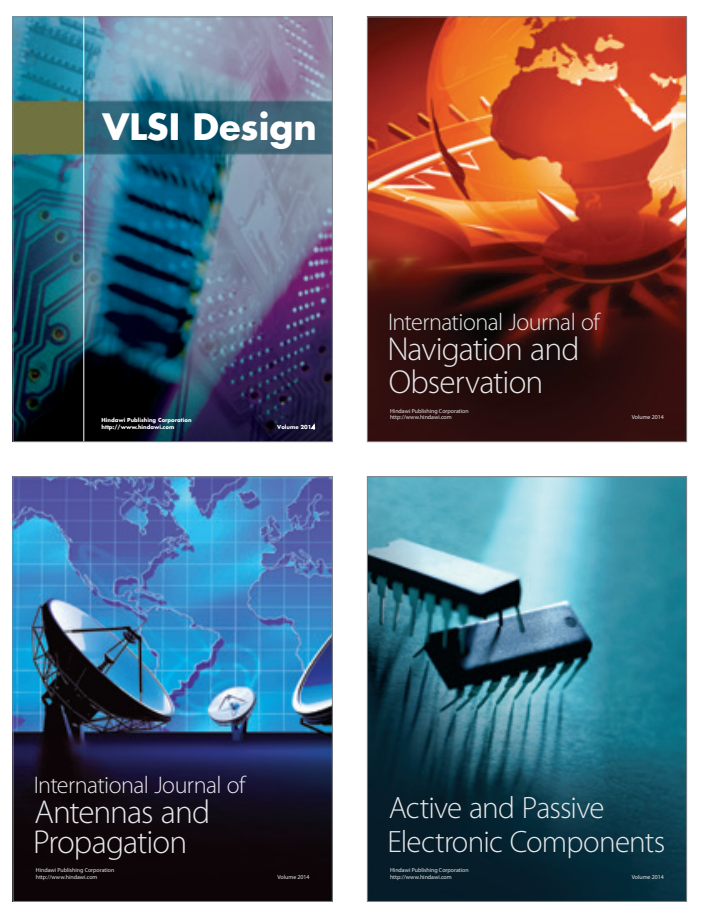
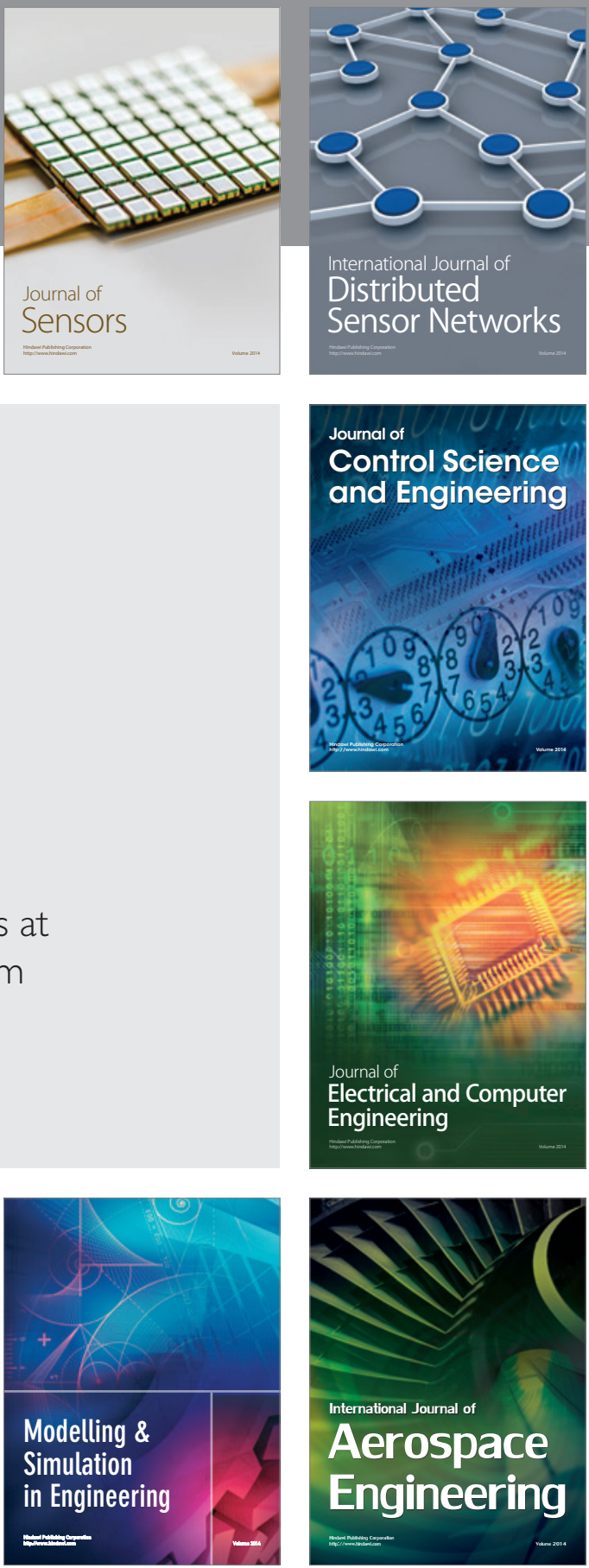

Journal of

Control Science

and Engineering
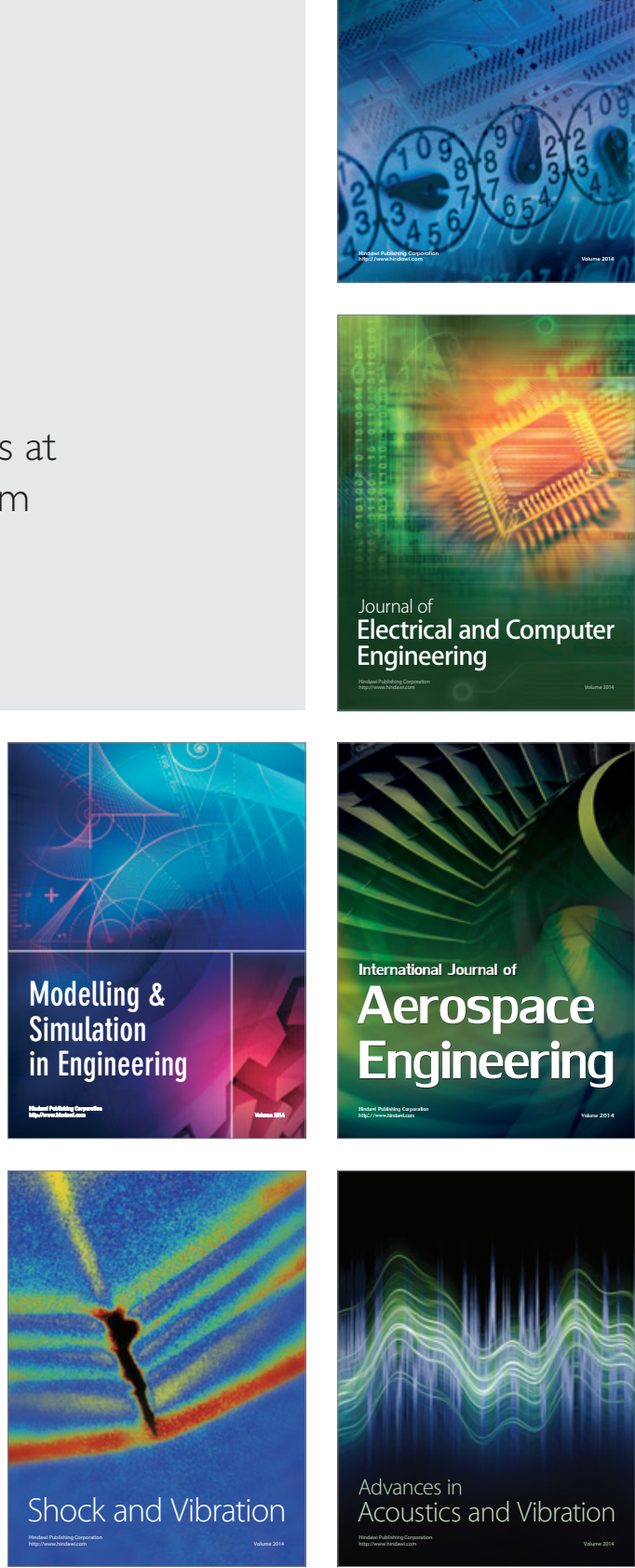